\title{
Author Correction: Strategic approaches to restoring ecosystems can triple conservation gains and halve costs
}

Bernardo B. N. Strassburg (D), Hawthorne L. Beyer, Renato Crouzeilles, Alvaro Iribarrem, Felipe Barros, Marinez Ferreira de Siqueira, Andrea Sánchez-Tapia (1), Andrew Balmford, Jerônimo Boelsums Barreto Sansevero, Pedro Henrique Santin Brancalion, Eben North Broadbent, Robin L. Chazdon, Ary Oliveira Filho, Toby A. Gardner,

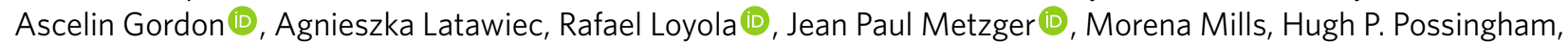
Ricardo Ribeiro Rodrigues, Carlos Alberto de Mattos Scaramuzza, Fabio Rubio Scarano, Leandro Tambosi (1D and Maria Uriarte

Correction to: Nature Ecology \& Evolution https://doi.org/10.1038/s41559-018-0743-8, published online 17 December 2018.

In the version of this Article originally published, the description of equation 1 in the Methods subsection 'Biodiversity conservation benefits' was incorrect.

The following sentence:

'On the basis of a previous study ${ }^{10}$, the change in extinction risk $(r)$ for each individual species as a function of habitat area was modelled as follows:

$$
r=1-\left(x / A_{0}\right)^{z}
$$

where $A_{0}$ is the current habitat area, $x$ is additional habitat area that would arise from habitat restoration, and the power $z$ describes the rate of diminishing returns in value of additional area at reducing extinction risk.'

should have read as follows:

'On the basis of a previous study ${ }^{10}$, the extinction risk $(r)$ for each individual species as a function of habitat area was modelled as follows:

$$
r=1-\left(x / A_{0}\right)^{z}
$$

where $A_{0}$ is the original habitat area, $x$ is the current habitat area (that could be increased through habitat restoration), and the power $z$ describes the rate of diminishing returns in value of additional area at reducing extinction risk.'

This error has now been corrected.

Published online: 23 April 2020

https://doi.org/10.1038/s41559-020-1211-9

(C) The Author(s), under exclusive licence to Springer Nature Limited 2020 